\title{
Alterations of the Rat Mesentery Vasculature in Experimental Diabetes
}

\author{
Kourosh Arshi, Moïse Bendayan, and Lucian D. Ghitescu \\ Département de Pathologie et Biologie Cellulaire, Université de Montréal, Montréal, Québec, Canada
}

\begin{abstract}
SUMMARY: The alteration induced by diabetes on vascular permeability to serum albumin was investigated in the mesentery of streptozotocin-induced hyperglycemic rats. Double-tagged ( ${ }^{125} \mathrm{I}$ and dinitrophenol-haptenated) heterologous albumin was intravenously administered in normal and hyperglycemic animals, and the extravasation of the tracer was evaluated by radioactivity measurements and by morphometry at the ultrastructural level using quantitative protein A-colloidal gold immunocytochemistry. The results demonstrate that diabetes induces a significant increase in the permeability of the mesentery vessels to albumin. This increase is due to a more efficient transport of macromolecules by endothelial plasmalemmal vesicles and not to leakier interendothelial junctions. Passage across the endothelial basement membranes did not appear to be restricted in either the control or diabetic condition. However, in diabetes, the mesothelial basement membrane appeared to become modified and to restrain the passage of albumin toward the peritoneal cavity. After 3 months of diabetes, the rats presented a net increase in the average diameter of the blood vessels localized in the mesentery arcada (macrovascular hyperplasy) and a notable angiogenesis, manifested at the level of the microvasculature in the mesenteric windows. (Lab Invest 2000, 80:1171-1184).
\end{abstract}

$T$ he association of diabetes with vascular dysfunctions gradually evolving toward incapacitating or life-threatening vascular pathologies is undisputed. Extensive clinical observations and studies on animal models have amply documented that hyperglycemia accelerates and worsens atherosclerosis in large arteries (Colwell et al, 1988; Shantaram, 1999; Steiner 1997) and affects, although in different ways, the microvessels of selected vascular beds, such as those of the retina (Bazan et al, 1997; Cunha-Vaz, 1983; Porta, 1996; Ruggiero et al, 1997), kidney (Flyvbjerg, 1997; Mauer et al, 1984; Nyengaard and Bendtsen, 1993; Vlassara et al, 1994), and nerves (Cameron and Cotter, 1997; Malik et al, 1993; Tesfay et al, 1994). Particular attention has been directed to the study of diabetes-induced retinopathies and nephropathies, because of their obvious clinical implications. On the other hand, the impact of diabetes on other vascular beds has been generally overlooked. Therefore, it is not known whether diabetic microangiopathy concerns all blood vessels, creating a sort of "dysfunctional background" exacerbated in particular tissues by local factors to a full blown vascular pathology, or the vasculature of many organs is simply spared by the deleterious effects of hyperglycemia/ hypoinsulinemia. The latter hypothesis would fall in line with the ever-growing body of evidence pointing

Received February 1, 2000.

This work was supported by a grant to MB from the Medical Research Council of Canada and grants to LG from the Association Diabète Québec and the Natural Sciences and Engineering Research Council of Canada.

Address reprint requests to: Lucian D. Ghitescu, Département de Pathologie et Biologie Cellulaire, Université de Montréal, CP 6128 Succ. CentreVille, Montréal, Québec, H3C 3J7, Canada. Fax: 514-343-5755; E-mail: ghitescd@patho.umontreal.ca to important physiological and biochemical dissimilarities between various vascular segments (Boegehold, 1998; Rajotte et al, 1998; Thorin and Shreeve, 1998).

Several morphologic features and physiologic parameters appear as leit motifs of diabetic microangiopathies. Among these, the thickening of the basement membrane is a general phenomenon encountered in both vascular (Fischer and Gaertner, 1983; Yasuda et al, 1990) and nonvascular tissues (Johnson, 1981). When related to cells not belonging to the vascular wall, this hypertrophy does not seem to play a clinically significant role. However, in the kidney, the basement membrane thickening profoundly alters the glomerular filtration (Bendayan et al, 1986; Mauer et al, 1984; Myers et al, 1982) and, in conjunction with the mesangial proliferation, compromises the function of this organ. It is considered that the hyperglycemic condition induces the endothelial cells to increase the synthesis and secretion of extracellular matrix proteins (Ayo et al, 1990; Cagliero et al, 1988; Roy et al, 1996).

An increased vascular permeability is another hallmark of diabetic microangiopathy (Beals et al, 1993; CunhaVaz et al, 1975; Kilzer et al, 1985; O'Hare et al, 1983; Parving, 1975,1976; Thüring et al, 1988; Trap-Jensen, 1971; Trap-Jensen and Lassen, 1968, 1970; Williamson et al, 1985, 1987). In fact, regulation of blood-tissue exchanges represents the essential endothelial function, and loss of this control could have important consequences for the integrity of the irrigated organ.

Vascular hypertrophy and angiogenesis also have been associated with diabetes, albeit only in selected organs (Lutty et al, 1996; Norrby et al, 1990a; Vranes et al, 1995a). This abnormal endothelial proliferation is at present explained by the expression, at the affected site, of endothelial growth factors, particularly the vascular endothelial growth factor (VEGF). Synthesis 
of this cytokine appears be stimulated by local ischemia (Armstrong et al, 1998) or by general factors such as high concentrations of glucose (Natarajan et al, 1997) and advanced glycation end products (Hirata et al, 1997).

The question addressed in this paper is whether vascular beds other than those generally known to be affected by diabetes (eye, kidney, and nerves) are also susceptible to alteration by this disease. Studies using radiolabeled albumin were carried out to evaluate vascular permeability in various blood capillary beds. Preliminary results have indicated that, among many tissues affected, vascular permeability of the mesenteric vessels is one of the most altered in diabetic conditions. We have therefore taken the mesentery vasculature as a model to investigate the diabetesinduced alterations on vascular permeability, basement membranes, and angiogenesis in this tissue.

\section{Results}

A simple visual inspection has shown that the mesentery harvested from diabetic animals has significantly less adipose tissue in the arcades than that of the normoglycemic rats. The main branches of the mesenteric arteries and veins appear to be comparatively swollen and the mesenteric windows, mostly avascular in control animals, present a notable microvascular development in diabetic rats. However, examination at light microscopy level (semithin sections of Eponembedded material) and low magnification electron microscopy does not reveal differences between diabetic and normal animals in mesentery thickness, edema, particular degranulation of the mast cells, or the integrity of endothelial and mesothelial cells (Fig. $1)$.

\section{Characterization of the Tracer}

An average of eight dinitrophenol (DNP) residues was introduced per molecule of albumin. Consequently, DNP-BSA became slightly more anionic than its native variant, as demonstrated by their electrophoretic migration in nondenaturing conditions (Fig. 2). However, it is well documented that dinitrophenylation induces few changes in albumin conformation (Kessler et al, 1982; Londoño et al, 1995) and that DNP-BSA carrying less than 10 DNP residues per molecule is cleared from circulation at a rate virtually identical to that of the native albumin (Kitteringham et al, 1985). Only a relatively small percentage (less than $8 \%$ as assessed by densitometry) of the tracer was found as a dimer, whereas the majority of DNP-BSA was in a monomeric form, even after storage at high concentrations.

\section{Global Evaluation of the Vascular Permeability to Albumin}

The global vascular permeability in the mesentery of normal and diabetic rats was assessed by recording ${ }^{125}$ I-DNP-BSA passage from the blood into the extravascular space. For comparison, two other tissues, the diaphragm and the anterior tibialis muscle, whose microvasculature is also endowed with a continuous type of endothelium, were similarly examined. The results, presented in Table 1, demonstrate that the vascular permeability to albumin is particularly elevated in the mesentery of diabetic animals, irrespec-

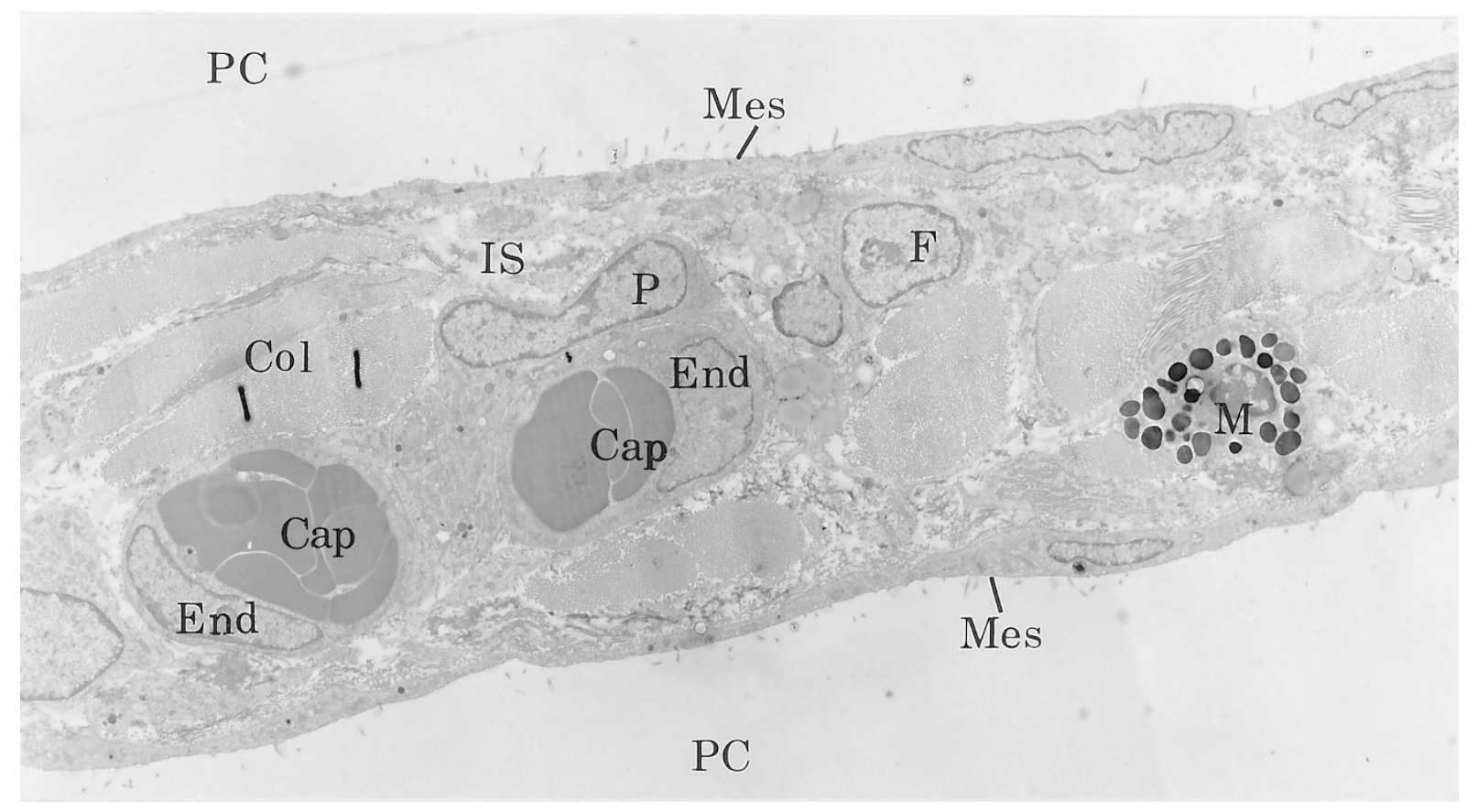

Figure 1.

Micrograph of the mesentery of a diabetic rat, illustrating the different components. Mes, mesothelial cells; $M$, mast cell; $F$, fibroblast; $P$, pericyte; End, endothelial cell; Cap, capillary; IS, interstitial space; Col, collagen fibers; $P C$, peritoneal cavity. Original magnification, $\times 1,600$. 


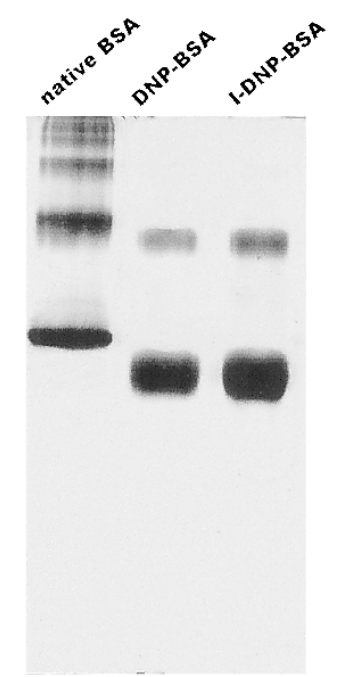

Figure 2

Comparative electrophoresis in nondenaturing conditions of native BSA, DNP-BSA, and I-DNP-BSA. Dinitrophenylation renders the albumin molecules slightly more anionic (migrating faster) than the native ones. In contrast to the commercial BSA, the injected tracer (I-DNP-BSA) is mostly in the form of monomers.

tive of the method of streptozotocin (STZ) administration (ip or iv). The animals received identical amounts of tracer $(2.01 \pm 0.05 \mathrm{~g}, n=20)$. In spite of the fact that the control rats averaged 1.5 times heavier than the diabetic animals, the specific ${ }^{51} \mathrm{Cr}$ and ${ }^{125} \mathrm{I}$ activity in the blood at 15 minutes circulation time was remarkably uniform among the experimental groups. Therefore, the clearance of the tracer from the blood does not show important differences between diabetic and normal animals, at least at 15 minutes circulation time. The amount of intravascular and extravascular ${ }^{125}$ I-DNP-BSA per milligram tissue weight increases in both diabetic groups (iv and ip) compared with controls. However these data had to be amended for differences in the mesentery mass (the fat loss in diabetes). The extravascular:intravascular ${ }^{125} \mathrm{I}$-DNPBSA ratio computed for each animal eliminates this variable. This ratio shows a value almost double for diabetic animals compared with the normoglycemic animals, and demonstrates that the egress of the macromolecular tracer from the vasculature of the mesentery is increased in diabetes. Statistically significant higher permeability for albumin was also recorded in the diaphragm of diabetic rats (Table 2). In contrast, the anterior tibialis muscle presents a low basal permeability and no diabetes-induced modifications were recorded. This muscle is, however, completely at rest (anesthetized animal) during the tracer administration and most of its microcirculation is likely to be shut off.

\section{Morphometric Assessment of the Permeability at the Ultrastructural Level}

The immunocytochemical detection of ${ }^{125}$ I-DNP-BSA in the mesentery of diabetic and normal rats was performed with an anti-DNP antibody, followed by protein A-gold complexes. It revealed the presence of the tracer over the vascular lumen, the endothelial cells, the endothelial basement membrane, the interstitium, the mesothelial basement membrane, as well as over the mesothelial cells (Fig. 3). Over the endothelial and mesothelial cell profiles, most of the gold particles were associated with the plasmalemmal vesicles, in accord with a vesicular mechanism of transcytosis. No abnormally opened interendothelial junctions were recorded in the diabetic rats, and consequently the intercellular junctions displayed little, if any, labeling (Fig. 3a). In fact, no notable ultrastructural differences were observed between the mesentery of the normal and diabetic animals, except for the intensity of the immunolabeling. The specificity of the ${ }^{125}$ I-DNP-BSA detection was confirmed by the fact that the anti-DNP antibodies do not recognize endogenous proteins and no signal was elicited on sections derived from animals that had not received the tracer.

Morphometric analysis of the labeling revealed a quite uniform density of gold particles within the vascular lumen in tissues from both normoglycemic and hyperglycemic animals. However, the mesentery from hyperglycemic animals displayed significantly higher densities of labeling in all the other compartments examined (Table 3). This increase was particularly notable (approximately 2-fold) over endothelial cell profiles, supporting the idea that in diabetes the endothelium takes up and transports more macromolecules from the blood to the tissue. Similar higher presence of the tracer was recorded within the endothelial basement membrane, whereas over the interstitium, the concentration of ${ }^{125} \mathrm{I}$-DNP-BSA was found to be only marginally, but significantly, increased, and with greater variations among the individual examined fields. These variations are accounted for by the intrinsic heterogeneous composition of the intercellular matrix (collagen bundles versus ground substance) and therefore by the local variations of the "available space" for soluble macromolecules. A second zone where the tracer seemed to concentrate is the mesothelial basement membrane (Table 3). No thickening of the basement membranes (endothelial and mesothelial) was observed. However, the permeability of the two seems to evolve differently in response to diabetes, as suggested by the pattern of the ${ }^{125}$ I-DNPBSA distribution across each of these basement membranes. This pattern was evaluated by measuring the ratio $(R)$ between the distance separating each gold particle from the abluminal plasma membrane $(d)$ and the basement membrane thickness $(D)$ at that same site (Fig. 4). These results are presented in Figure 5. The distribution of gold particles across the endothelial basement membranes seems almost uniform in both normal and hyperglycemic animals. For the mesothelial basement membrane, however, the hyperglycemic condition induced an asymmetric profile for albumin distribution (Fig. 5). About $50 \%$ of the ${ }^{125} \mathrm{I}$-DNP-BSA labeling was concentrated at the distal side of the basement membrane at the edge with interstitial space (Figs. 4 and 5). This indicates that a 
Table 1. Intravascular vs. Extravascular Distribution of ${ }^{125}$ I-DNP-BSA in the Mesentery of Normal and Diabetic Rats

\begin{tabular}{|c|c|c|c|c|c|c|}
\hline \multirow[b]{2}{*}{ Animals } & \multirow[b]{2}{*}{ Body weight } & \multicolumn{2}{|c|}{ Blood } & \multicolumn{3}{|c|}{ Mesentery } \\
\hline & & $\begin{array}{l}\text { Specific activity } \\
\text { of the }{ }^{125} \text { | } \\
(\mathrm{cpm} / \mu \mathrm{l})\end{array}$ & $\begin{array}{l}\text { Specific activity } \\
\text { of the }{ }^{51} \mathrm{Cr} \\
(\mathrm{cpm} / \mu \mathrm{l})\end{array}$ & $\begin{array}{l}\text { Intravascular } \\
\text { albumin } \\
\text { ( } \mu \mathrm{g} / \mathrm{mg} \text { tissue) }\end{array}$ & $\begin{array}{l}\text { Extravascular } \\
\text { albumin } \\
\text { ( } \mu \mathrm{g} / \mathrm{mg} \text { tissue) }\end{array}$ & $\begin{array}{c}\text { Extravasc. } \\
\text { albumin/Intravasc. } \\
\text { albumin }\end{array}$ \\
\hline Control rats $(\mathrm{n}=8)$ & $474 \pm 29.10$ & $8.26 \pm 0.52$ & $19.4 \pm 1.17$ & $0.25 \pm 0.07$ & $0.13 \pm 0.03$ & $0.51 \pm 0.06$ \\
\hline Diabetic iv $(n=3)$ & $308 \pm 19.80$ & $9.10 \pm 0.54$ & $21.8 \pm 1.20$ & $1.25 \pm 0.35^{\dagger}$ & $0.94 \pm 0.11^{\dagger}$ & $0.90 \pm 0.05^{\dagger}$ \\
\hline Diabetic ip $(n=9)$ & $288 \pm 8.13$ & $8.89 \pm 0.29$ & $22.1 \pm 0.64$ & $1.01 \pm 0.08^{\dagger}$ & $0.98 \pm 0.13^{\dagger}$ & $1.21 \pm 0.15^{\dagger}$ \\
\hline
\end{tabular}

Animals were rendered diabetic by either iv or ip injection of STZ. Data are means \pm SEM and $n=$ number of animals for each group.

${ }^{\dagger} p \leq 0.005$ vs. age-matched group (Student's $t$ test).

Table 2. Intravascular and Extravascular Distribution of ${ }^{125} \mathrm{I}$-DNP-BSA in the Diaphragm and Tibialis Anterior Muscle of Rat

\begin{tabular}{cccccc}
\hline & \multicolumn{2}{c}{ Diaphragm } & & \multicolumn{2}{c}{ Tibialis anterior } \\
\cline { 2 - 3 } & $\begin{array}{c}\text { Intravascular } \\
\text { albumin } \\
\text { Animals }\end{array}$ & $\begin{array}{c}\text { Extravascular } \\
\text { albumin } \\
(\mu \mathrm{g} / \mathrm{mg} \text { tissue })\end{array}$ & & $\begin{array}{c}\text { Intravascular } \\
\text { albumin } \\
(\mu \mathrm{g} / \mathrm{mg} \text { tissue })\end{array}$ & $\begin{array}{c}\text { Extravascular } \\
\text { albumin }\end{array}$ \\
$(\mu \mathrm{g} / \mathrm{mg} \mathrm{tissue})$
\end{tabular}

Animals were rendered diabetic by either iv or ip injection of STZ. Data are expressed as the mean value \pm SEM. $n=$ number of animals for each group.

${ }^{\dagger} p \leq 0.005$ vs. age-matched group (Student's $t$ test).

barrier limiting albumin diffusion out of the mesentery toward the intraperitoneal cavity was established at this level.

\section{Diabetes-Induced Angiogenesis in Mesenteric Windows}

In this part of the study, we quantified the density of the microvascular bed irrigating five selected mesenteric windows from a group of normoglycemic animals containing 1) rats that received no drug or saline vehicle (Control), and 2) rats injected ip with STZ, which did not become hyperglycemic (ip Negative). We compared these two groups with the same anatomical entities harvested from 3) rats rendered hyperglycemic by iv administration of STZ (iv Positive), and 4) rats injected ip with STZ and sustaining diabetes (ip Positive).

A significant increase in the vascularized area, the number of vascular ramifications, and the length of the vessels between two successive ramifications was registered for both groups of diabetic rats (Fig. 6). The mean relative vascularized area of iv Positive and ip Positive groups were found to be 7 -fold and 12-fold greater than that in the control group, respectively (Table 4). Not unexpectedly, angiogenesis was also detected in the ip Negative group, albeit at a significantly smaller scale than in hyperglycemic animals.

\section{Diabetes-Induced Hypertrophy of Mesenteric Large Vessels}

Compared with the control group, the diabetic rats demonstrated a clear increase in the diameter of the vessels found in their mesenteric arcada (Fig. 7). Using the Mann-Whitney statistical test, a significant difference at the $95 \%$ confidence level was found for each of the ten 100- $\mu \mathrm{m}$ wide domains (30 $\mu \mathrm{m}$ to $1030 \mu \mathrm{m}$ ) into which the vessels (arteries and veins together) were distributed. An average diameter of $256.8 \pm 12.4$ $\mu \mathrm{m}$ (mean $\pm \mathrm{SEM}$ ) was computed for the vessels in the arcada of the diabetic rats, compared with $190.0 \pm$ $10.7 \mu \mathrm{m}$ for the control group ( $n=360$ and 180, respectively).

\section{Discussion}

The results presented in this paper show that STZinduced diabetes produces significant alterations in the mesenteric blood vessels, a vascular bed that is different from the classical targets of diabetic microangiopathy, the retina and the kidney. These alterations are reported as increased permeability to macromolecules, vascular hyperplasy, and angiogenesis. To demonstrate the changes in permeability, diabetic and normal rats were injected iv with a double-tagged tracer, ${ }^{125}$ I-DNP-BSA, whose fate in circulation has been previously shown to be virtually identical to that of the native, endogenous serum albumin (Ghitescu and Bendayan, 1992; Kitteringham et al, 1985). This experimental design preserved all of the essential conditions (presence of plasma proteins, blood cells, and normal hemodynamic factors) for an unbiased assessment of the vascular permeability under physiological conditions. Furthermore, application of the post-embedding immuno-gold method on mesenteric tissue allows for the high-resolution localization of those circulating albumin molecules retained in situ by the fixation procedure, injection of the albumin allow- 


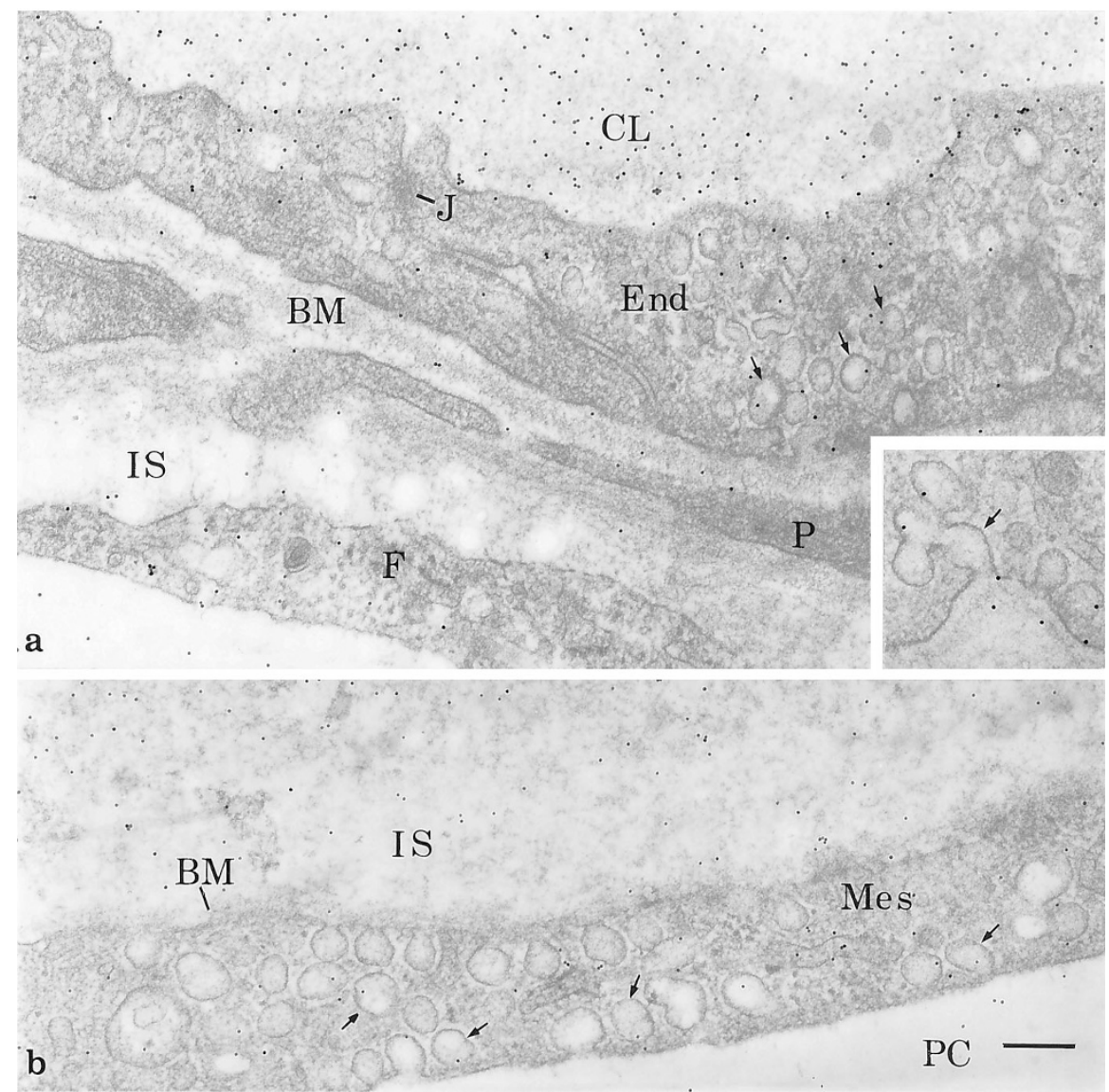

\section{Figure 3.}

Immunocytochemical detection of DNP-BSA across the rat mesentery. a, Blood capillary area. Intense labeling is present over the capillary lumen (CL). More discreet labeling is located over the capillary endothelial cells (End), particularly associated with the vesicular structures (arrows) and vesiculo-tubular structures (inset). Some gold particles are seen over the endothelial basement membrane $(B M)$ and the interstitial space $(I S)$. The intercellular junction $(J)$ is free of labeling. $b$, Mesothelium. Over the mesothelial cell (Mes) the labeling is also associated with the vesicular structures (arrows). $P$, pericyte; $F$, fibroblast; $P C$, peritoneal cavity. Bar $=0.2 \mu \mathrm{m}$

Table 3. Labeling Density Distribution for DNP-BSA in Various Compartments of the Rat Mesentery

\begin{tabular}{ccccccc}
\hline Animals & $\begin{array}{c}\text { Vascular lumen } \\
(\%)\end{array}$ & $\begin{array}{c}\text { Endoth. profile } \\
(\%)\end{array}$ & $\begin{array}{c}\text { Endoth. BM } \\
(\%)\end{array}$ & $\begin{array}{c}\text { Interstitium } \\
(\%)\end{array}$ & $\begin{array}{c}\text { Mesoth. BM } \\
(\%)\end{array}$ & $\begin{array}{c}\text { Mesoth. profile } \\
(\%)\end{array}$ \\
\hline Control rats & 100 & $9.71 \pm 0.72$ & $9.32 \pm 0.76$ & $10.64 \pm 0.43$ & $13.46 \pm 0.42$ & $7.83 \pm 0.22$ \\
Diabetic rats & 100 & $16.30 \pm 1.77^{\dagger}$ & $18.88 \pm 1.74^{\dagger}$ & $13.91 \pm 0.51^{\dagger}$ & $26.04 \pm 0.72^{\dagger}$ & $8.88 \pm 0.28^{\dagger}$ \\
\hline
\end{tabular}

The labeling density is expressed as the percentage of that of the vascular lumen. MB $=$ basement membrane. Data are means \pm SEM for 80 examined profiles.

${ }^{\dagger}$ Significantly different from corresponding compartment of normoglycemic animals (Student's $t$ test, $p<0.05$ ).

ing for the physiological distribution of these molecules. This approach contrasts with methods using electron-dense tracers or albumin-gold complexes introduced into the circulation, with adverse effects on vascular permeability (Simionescu, 1979; Villaschi et al, 1986; Yamaji et al, 1993).

The ip administration of STZ is suspected to produce, by simple irritation, non-specific effects on the abdominal vasculature. To counter this, diabetes was induced in several rats by iv administration of the drug, and these animals were treated as a separate experimental group, parallel to those ip injected.

Radioactive measurement of the global extravascular versus intravascular distribution of the tracer in the mesentery has shown that both these pools increase significantly in diabetic animals (Table 1). The computed ratio between the extravascular and intravascular iodinated albumin eliminates the contribution of the differences in mesentery mass between normal and diabetic animals and represents, in our view, a closer evaluation of the transmural vascular transport process. Our results further substantiate the idea that in diabetic rats, albumin crosses the mesenteric vessel wall faster or in higher amounts. No difference was found related to the way diabetes was induced (iv or ip administration of STZ). This effect of diabetes on endothelial transcytosis of albumin does not appear to be restricted to the mesentery; another vascular bed endowed with a continuous type of endothelium, the diaphragm, which was permanently irrigated during the 


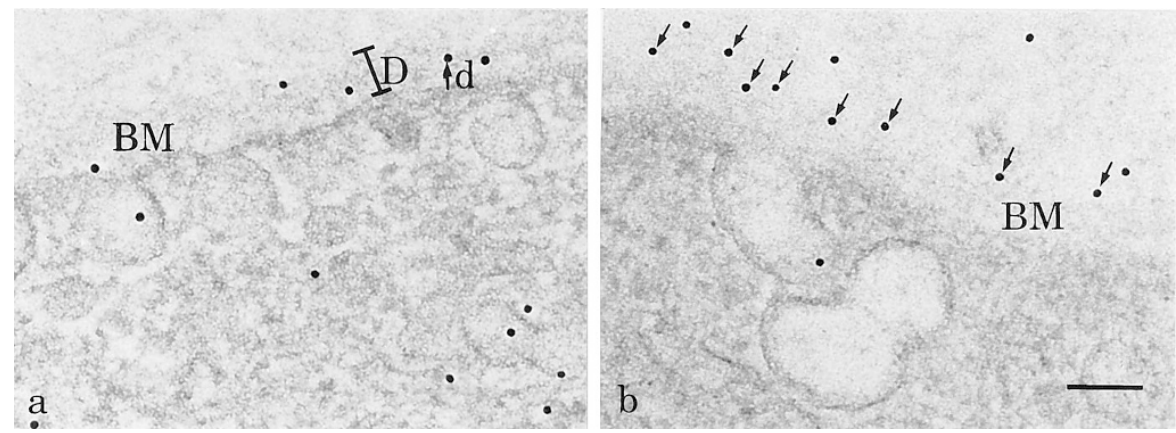

\section{Figure 4}

Localization of DNP-BSA across the mesothelial basement membrane in the mesentery of (a) control and (b) diabetic rats. Most of the gold particles are located at the edge of mesothelial basement membrane in tissues of diabetic animals (arrows), demonstrating a relative restriction of the passage of albumin in chronic hyperglycemia. Morphometric distribution of the labeling across the basement membrane was determined by evaluation of $R=d / D$, where $d$ is the distance from the plasma membrane to the gold particle, and $D$ is the thickness of the basement membrane at the same site. Bar $=0.1 \mu \mathrm{m}$.

15 minutes circulation time of the tracer, also shows a higher permeability to albumin in diabetic animals (Table 2). We interpret the low permeability recorded in the anterior tibialis muscle of normal rats and the lack of any detectable alterations in their diabetic counterparts as a consequence of the minimal perfusion of this muscle under anesthesia and immobilization.

A second level of investigation in this study concerned the mechanism by which the vascular permeability increases in diabetes. This question is inexorably related to the ongoing debate between the vesicular transcytotic model (Palade, 1960), the existence of patent transendothelial channels (Bendayan et al, 1975; Simionescu et al, 1975), and the belief that the interendothelial junction space represents the main pathway for the passage of macromolecules from blood to the tissue (Landis and Pappenhaimer, 1963). DNP attached to BSA allowed us to immunocytochemically localize the tracer with high resolution, at the ultrastructural level, in compartments relevant for the process of transcytosis. The quantitative relationship between the density of colloidal gold immunolabeling and the actual concentration of the detected molecule has been demonstrated (Ghitescu and Bendayan 1992; Griffith and Hoppeler, 1986; Slot et al, 1989) and is generally accepted. At 15 minutes circulation time, the tracer is still far from reaching an equilibrium between the vascular lumen and the interstitium (Ghitescu, Bendayan, 1992). Because of this large transendothelial gradient, the putative ${ }^{125}$ I-DNPBSA flux through the interendothelial junctions would be at its maximal value and therefore easily detected as a large population of haptenated molecules in transit through the junctional space. In contrast to this expectation, the immunocytochemical detection of the ${ }^{125}$ I-DNP-BSA over the capillary profiles of the mesenteric windows has revealed only a very scarce labeling of the interendothelial clefts, in both normal and diabetic rats. Instead, the tracer was found to be entirely associated with the endothelial plasmalemmal vesicles. This is in accord with previous studies demonstrating that transendothelial passage of large circulating proteins does take place through the shuttling of vesicular structures or through the vesicular-tubular endothelial system. In diabetic animals, the intensity of the labeling over this compartment nearly doubled in respect to the controls (Table 3 ). Our results thus demonstrate that the mechanism by which diabetes enhances the capillary permeability to macromolecules in vivo does not involve the opening of interendothelial clefts, but rather an increased accessibility of circulating proteins to plasmalemmal vesicles. It has already been reported that large albumin-colloidal gold complexes-perfused in situ through the rat heart vasculature, in spite of not being a physiological tracer, are taken up by the endothelial caveolae in higher amounts in diabetic than in normal animals (Yamaji et al, 1993).

Our immunocytochemical approach has found smaller differences, although statistically significant, between the tracer concentration within the interstitial space of the mesentery of hyperglycemic and normoglycemic rats. This is due to the fact that, as already mentioned, the albumin that has crossed to the relatively large interstitial compartment has not yet reached its equilibrium with the intravascular pool. Moreover, the composition of the interstitium is very heterogeneous (tightly packed collagen bundles versus loose connective tissue). This translates into a highly variable regional distribution of the "available spaces" for soluble molecules such as our tracer, and makes more difficult a precise quantitation, in the conditions of the limited sampling specific for the ultrastructural morphometry. However, at the level of the endothelial basement membrane, a morphologically more uniform and better-defined compartment, the intensity of the labeling was double in diabetic versus the normoglycemic animals. The gold particles localizing the tracer were distributed through the entire profile of the endothelium and were not concentrated near the abluminal interendothelial cleft openings. No thickening of the basement membrane was observed in our model (animals at 3 months of diabetes). This does not contradict the current knowledge, as the accumulation of material in this structure becomes visible at later stages of the disease (Bendayan et al, 1986; Doucet et al, 2000; Hirose et al, 1982; Østerby, 1986). The rather uniform distribution of ${ }^{125}$ I-DNP- 


\section{ENDOTHELIAL BASEMENT MEMBRANE}

Control Rats

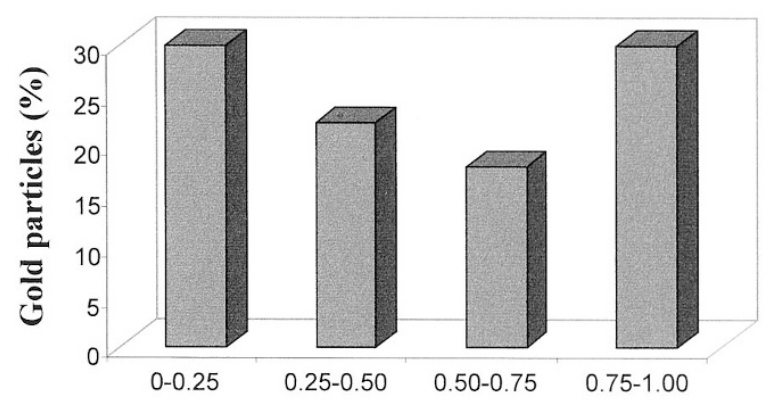

Relative distance from abluminal PM (R)
Diabetic Rats

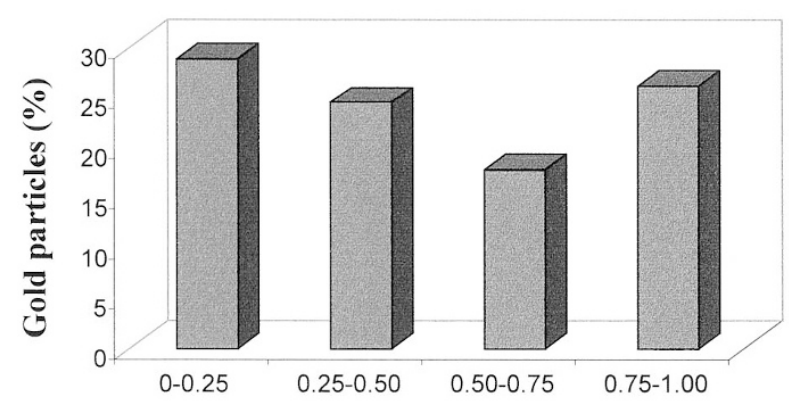

Relative distance from abluminal PM (R)

\section{MESOTHELIAL BASEMENT MEMBRANE}

Control Rats

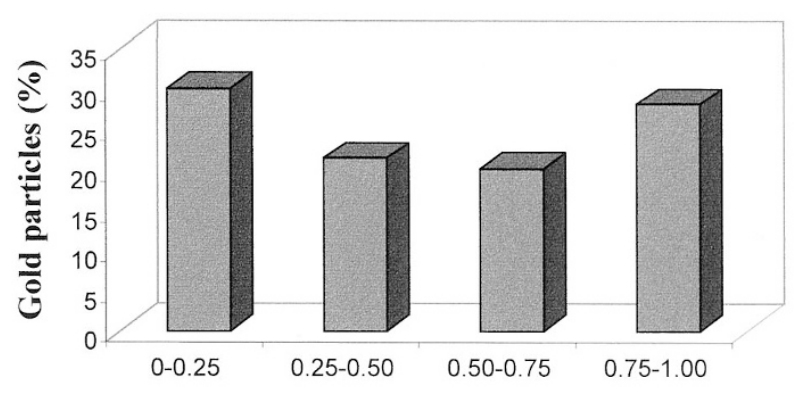

Relative distance from abluminal PM (R)
Diabetic Rats

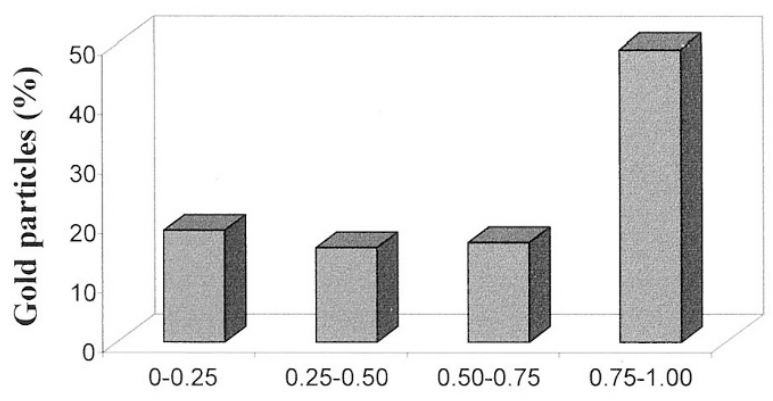

Relative distance from abluminal PM (R)

\section{Figure 5.}

Histograms demonstrating the distribution of gold particles across the endothelial and mesothelial basement membranes of diabetic and age-matched control rats. $R=d / D$ represents the relative distance separating the gold particles from the abluminal plasma membrane (PM). A value of 0 localizes the gold particles directly at the PM, whereas a value of 1.0 is attributed to the outermost particles. For the endothelial basement membrane, the evaluation was performed on 74 profiles (300 gold particles) and 71 profiles (184 gold particles) for diabetic and control groups, respectively. For the mesothelial basement membrane, the evaluation was performed on 62 mesothelial profiles (318 particles) and 68 mesothelial profiles (252 gold particles) from diabetic and control groups, respectively. The distribution of BSA across the endothelial basement membrane is almost uniform for both the diabetic and control groups, whereas for the mesothelium in diabetic condition, the labeling for albumin is confined to the interstitial part of the mesothelial basement membrane. The control group does not display such an asymmetric distribution.

BSA in a plane perpendicular to the abluminal front of the endothelium indicates that the endothelial basement membrane does not restrict the diffusion of albumin-size molecules across its thickness (Fig. 5). This fact does not change in diabetes. In contrast, the mesothelial layer seems to evolve during diabetes toward establishing a semipermeable barrier to albumin; the tracer was found to accumulate in significant amounts at the distal, interstitial side of the mesothelial basement membrane (Figs. 4 and 5), suggesting a reduction in the porosity of the lamina densa. This might represent an adaptive effect, designed to prevent a high egress of plasma proteins into the peritoneal cavity and the development of ascites. It is interesting that in the mesentery, endothelial and mesothelial cells share a common embryonic origin, are embedded in the same extracellular matrix, and are submitted to identical hyperglycemic conditions. However, the evolution of their basement membranes in diabetes seems to differ, sggesting the existence of cell-type-specific mechanisms for the expression and assembly of extracellular matrix proteins. 

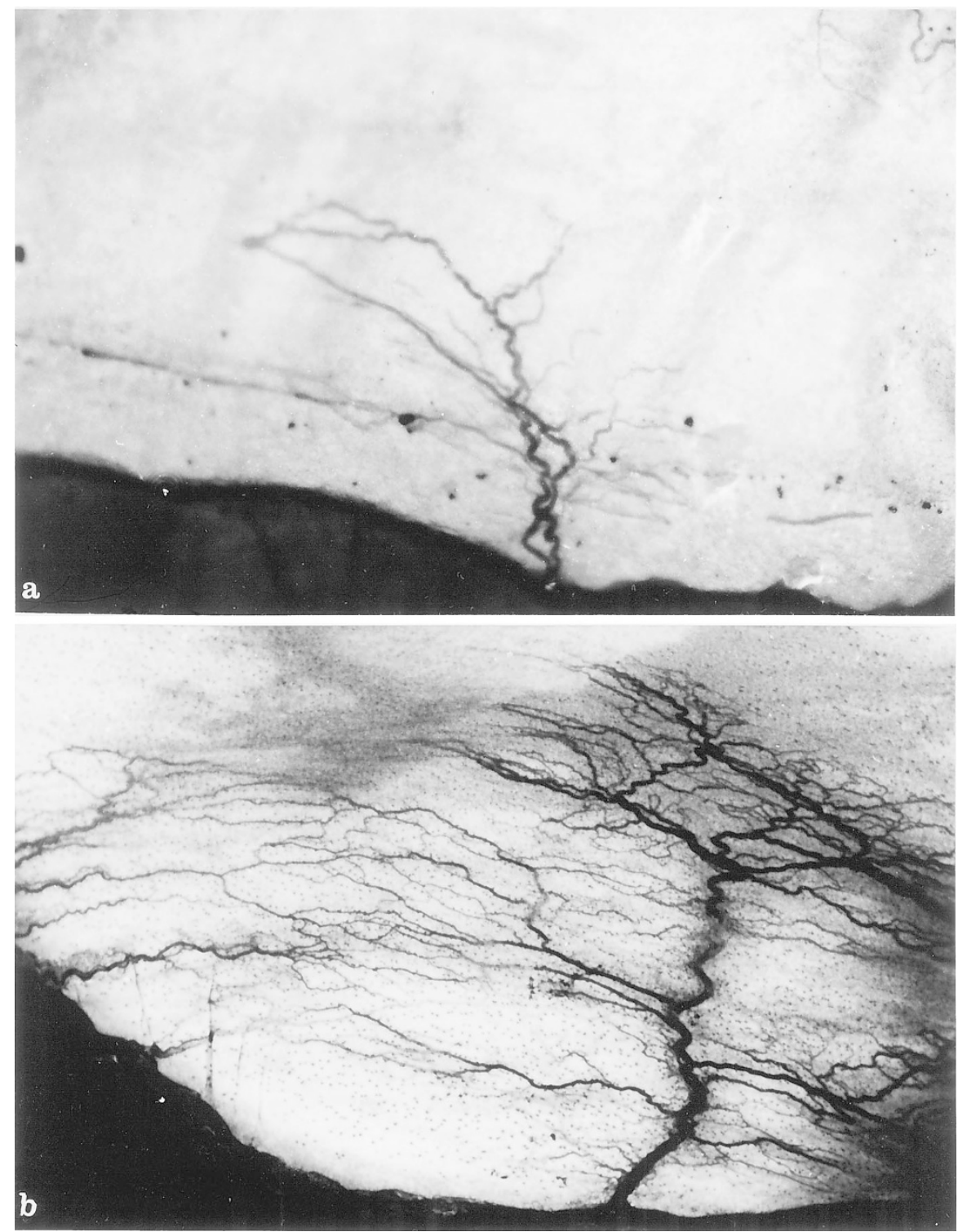

\section{Figure 6.}

Spread mesenteric windows in which the vessels are clearly outlined after staining with toluidine blue. a, Part of mesenteric window from a control rat; and b, from a 3-months diabetic rat. Note the marked increase in the density of the microvascularization (length of the vessels and incidence of branching) in the mesentery window harvested from a diabetic animal (b), in contrast to that of a normal animal (a). Diabetes was induced by iv injection of STZ.

The significant increase in the blood volume recorded per gram of tissue weight in the mesentery of diabetic animals is accounted for by two related phenomena: 1) a net increase in the average diameter of the supply vessel in the arcada, and 2) an angiogenic process responsible for a sustained development of a microvascular network in the mesentery windows, mostly avascular in normal animals. The vascular hypertrophy associated with diabetes has already been documented by other studies (Vranes et al, 1995b, 1999). The pro-angiogenic consequences of ip injected STZ have been previously described (Norrby et al, 1990b) and related to mast cell degranulation and histamine release. Our data show that the diabetic condition per se was able to trigger the mesentery blood vessels growth. In a chronic hyperglycemic state obtained by iv administration of the drug, a marked increase in the vascularized area of mesenteric windows was associated with an increase in the length and number or ramifications of the mesentery vessels (Table 4). Moreover, a comparison between the vascular networks developed in the mesentery of the ip Positive group and the ip Negative group demonstrates a significant increase in the length and vessel ramifications in the former group (Table 4), and underlines the role of hyperglycemia in the induction of angiogenesis.

This angiogenic effect in the mesentery of diabetic rats can be conveniently explained in the light of the recent facts and theories on the role of the VEGF. VEGF is a cytokine known for its ability to enhance the transport of substances across the vascular wall and to promote vascular growth (Neufeld et al, 1999). Therefore, it has been implicated in the pathogenic 
Table 4. Quantification of the Angiogenesis in Rat Mesentery

\begin{tabular}{cccc}
\hline Animals & $\begin{array}{c}\text { Vascularized } \\
\text { area (\%) }\end{array}$ & $\begin{array}{c}\text { Vessel } \\
\text { ramifications } \\
\text { (no/vasc. area) }\end{array}$ & $\begin{array}{c}\text { Total length } \\
\text { of vessels } \\
\text { (mm/vasc. area) }\end{array}$ \\
\hline Control rats & $2.63 \pm 0.07$ & $4.20 \pm 0.55$ & $4.83 \pm 0.42$ \\
ip Negative & $18.92 \pm 4.29$ & $41.46 \pm 8.88$ & $37.34 \pm 7.03$ \\
iv Positive & $16.08 \pm 1.14^{\dagger}$ & $79.53 \pm 17.70$ & $71.15 \pm 11.32$ \\
ip Positive & $37.08 \pm 3.87^{\dagger}$ & $195.93 \pm 17.04^{\dagger \ddagger}$ & $144.56 \pm 9.32^{\dagger \ddagger}$ \\
\hline
\end{tabular}

Control animals = animals that did not receive any drug or saline vehicle, ip Negative = rats that were injected ip with STZ, but no high levels of glycemia were detected, iv Positive = rats with injection iv with STZ, which developed chronic hyperglycemia, ip Positive $=$ rats that were injected ip with STZ, and sustained chronic hyperglycemia. Data are means \pm SEM for 15 mesenteric windows of each animal group.

${ }^{\dagger} p \leq 0.05$ vs. age-matched control animals, ${ }^{\ddagger} p \leq 0.05$ vs. ip Negative group (Student's $t$ test).

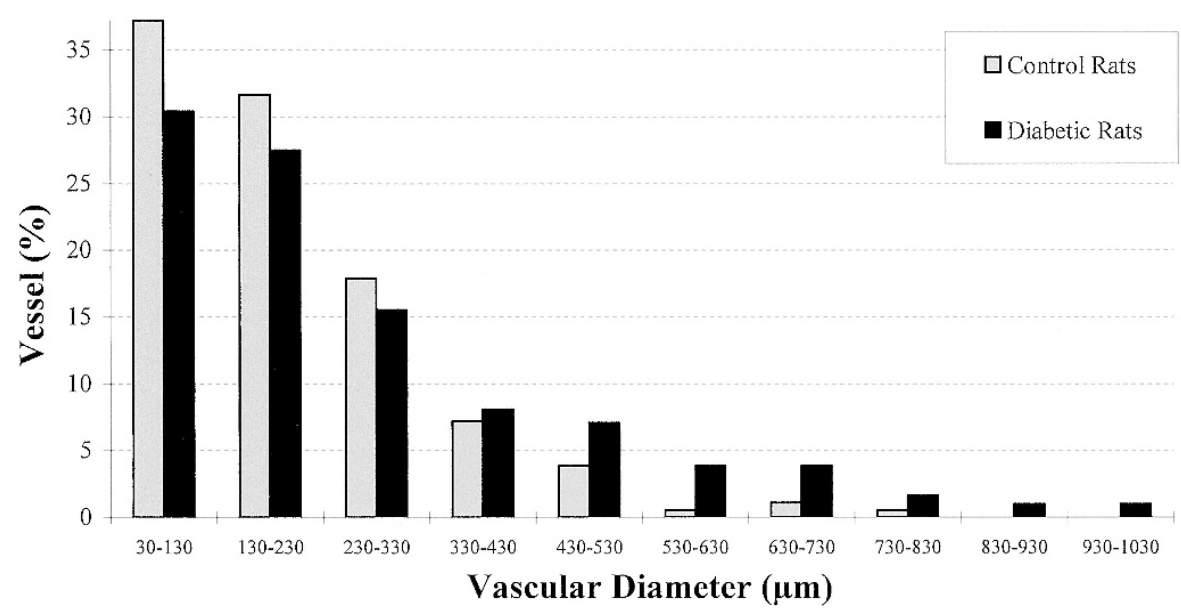

Figure 7.

Histogram demonstrating the vascular size distribution in mesenteric arcades for diabetic and control animals. A total of 309 and 180 vessels were evaluated for the diabetic and control groups, respectively.

neovascularization of the retina associated with diabetes (Aiello et al, 1995; Lutty et al, 1996). Factors such as hypoxia (Pe'er et al, 1995; Shweiki et al, 1992) and advanced glycation end-products (Renard et al, 1997) have been shown to enhance VEGF expression in vivo, and it was recently reported that hyperglycemia is able by itself to increase the intracellular level of VEGF mRNA in cultured smooth muscle cells and to induce a higher secretion of the peptide (Natarajan et al, 1997; Williams et al, 1997).

Less evident is the mechanism by which VEGF, also known as the vascular permeability factor, increases the permeability of mesenteric blood vessels to albumin. Several studies have shown that both in vitro and in vivo, VEGF is able to dictate a phenotypic change of growing endothelial cells toward the fenestrated kind (Esser et al, 1998; Roberts and Palade, 1997). We did not find any fenestrations in the microvascular network grown in the mesenteric windows of diabetic rats, explaining the recorded hyperpermeability. Our results suggest that the contribution of the endothelial caveolar compartment to albumin transcytosis becomes more important in diabetes. This contradicts a recent report according to which, in cultured umbilical vein endothelial cells, VEGF induces a dramatic downregulation of caveolin-1 and a diminution in the num- ber of cell-surface caveolae (Liu et al, 1999), but agrees with another study performed on retinal endothelium, in which VEGF seemed to increase the expression of its caveolar-associated Flk-1/KDR receptor (Feng et al, 1999).

\section{Materials and Methods}

\section{Animals}

Male Sprague Dawley albino rats (Charles River, St. Constant, Québec, Canada) of $100 \mathrm{~g}$ body weight were used in this study. Hyperglycemia was induced with STZ (Sigma Chemical Co, St. Louis, Missouri) either through ip $(70 \mathrm{mg} / \mathrm{kg}$ body weight) or iv (40 $\mathrm{mg} / \mathrm{kg}$ body weight) injections after an overnight fast. The iv pathway for STZ administration was used because reports in the literature have suggested that nonspecific, mast cell stimulation by simple ip irritation can induce angiogenesis in the mesentery (Malcherek and Franzén, 1991; Norrby et al, 1990). The animals were housed in individual cages and fed ad libitum with standard diet (Prolab Chow, Agway, Syracuse, New York) and water. Hyperglycemic animals showed lower weight gain and strong hyperglycemia (over 15 mmoles/l). 


\section{Experiments Assessing the Endothelial Permeability}

We evaluated the transendothelial passage of a heterologous plasma protein, bovine serum albumin (BSA), in the vascular bed of rat mesentery. The tracer (BSA) was simultaneously tagged with ${ }^{125}$ I and DNP, and iv injected in rats that had demonstrated chronic hyperglycemia for a period of 3 months, and in agematched controls. After 15 minutes in circulation, the BSA extravasation was assessed at two levels: 1) a global radioactive measurement of the intravascular versus extravascular distribution of the tracer in the above-mentioned tissue, and 2) a quantitative, morphometric study, at the ultrastructural level, of the BSA presence in compartments relevant to the vascular transport process (vascular lumen, endothelium, extracellular matrix, and mesothelial profiles). The hapten (DNP), covalently linked to BSA molecules, helped to detect the tracer by protein A-colloidal gold immunocytochemistry, using anti-DNP antibodies.

Preparation of the Tracer. Crystallized BSA was purchased from Sigma Chemical, St. Louis, Missouri; 2,4 dinitrobenzene sulfonic acid was from Aldrich Chemical, Milwaukee, Wisconsin; $\mathrm{Na}^{125}$ I, carrier free, was from ICN Biochemicals, Missisauga, Ontario, Canada; and chloramine $\mathrm{T}$ immobilized on polystyrene beads (lodo-Beads) was from Pierce Chemical, Rockford, Illinois. The tracer preparation procedure was similar to that described previously (Ghitescu and Bendayan, 1992). In brief, BSA was tagged with DNP according to the method of Little and Eisen (1967). Monomeric dinitrophenylated albumin (DNP-BSA) was obtained by gel chromatography on a Sephadex G-200 column and concentrated by ultrafiltration to $120 \mathrm{mg} / \mathrm{ml}$. The average number of DNP residues introduced per BSA molecule was evaluated spectrophotometrically and found to be about eight. Further, the DNP-BSA was radioiodinated using lodo-Beads according to manufacturer's instructions. The iodinated protein was freed of unreacted iodine by chromatography on Sephadex G-25, extensive dialysis against phosphate buffered saline (PBS), and concentrated to the original concentration and a specific activity of $1330 \mathrm{cpm} / \mu \mathrm{g}$ protein by ultrafiltration on a membrane with a $30 \mathrm{kD}$ cut-off limit (Centricone 30, Amicon, Beverly, Massachusetts). Comparative measurement of the ultrafiltrate and of the retentate indicated that only $0.3 \%$ of the ${ }^{125} \mathrm{I}-(\mathrm{DNP}-\mathrm{BSA})$ radioactivity could be associated with free iodine.

${ }^{51} \mathrm{Cr}$-labeled red blood cells were used to measure the blood volume in the examined tissues. Three milliliters of erythrocytes, obtained from heparinized rat blood, were incubated with $100 \mu \mathrm{Ci} \mathrm{Na}{ }^{51} \mathrm{CrO}_{4}$ (Parker et al, 1979), washed repeatedly with PBS, stored at 50\% hematocrit and $5.2 \times 10^{6} \mathrm{cpm} / \mathrm{ml}$ specific activity, and used within 3 days of preparation. Stock ${ }^{125} \mathrm{I}-(\mathrm{DNP}-\mathrm{BSA})$ and ${ }^{51} \mathrm{Cr}$ erythrocytes were mixed with cold DNP-BSA $(120 \mathrm{mg} / \mathrm{ml})$ to give the final tracer, which was injected into the animals.

General Experimental Approach. Hyperglycemic and age-matched normoglycemic animals (12 and 8 rats, respectively) were anesthetized by intra- abdominal injection of urethane $(0.75 \mathrm{mg} / \mathrm{kg}$ body weight), and $2 \mathrm{ml}$ of blood was withdrawn from the external jugular vein, using a No. 25 heparinized needle. The same volume of prewarmed $\left(37^{\circ} \mathrm{C}\right)$ radioiodinated DNP-BSA $\left(2.2 \times 10^{6} \mathrm{cpm}\right)$ mixed with ${ }^{51} \mathrm{Cr}$-labeled rat erythrocytes $\left(3.8 \times 10^{5} \mathrm{cpm}\right)$ was immediately injected. The syringes were weighed before and after the procedure to assess the uniformity of the injected doses. The whole operation took 1 to 2 minutes.

The tracer was maintained in circulation for a period of 15 minutes and, before the animals were killed by cervical dislocation, a drop of blood was collected from each animal. Fifty microliters of the blood samples was counted in duplicate by gamma spectrometry to measure the amounts of intravascular radiolabeled DNP-BSA and erythrocytes.

The mesentery was fixed in situ for 15 minutes by intra-abdominal injection of $2.5 \%$ formaldehyde and $1.5 \%$ glutaraldehyde in $100 \mathrm{~mm}$ phosphate buffer at $37^{\circ} \mathrm{C}$. On opening the abdominal cavity, the whole mesentery was removed, dissected free of intestines, weighed, and maintained in the same fixative overnight at $4^{\circ} \mathrm{C}$. The in situ fixation was sufficient to prevent any blood loss during the dissection.

Radioassay. Blood aliquots and harvested tissues were counted for the two isotopes in a gamma counter (1282 Compugamma, LKB, Bromma, Sweden), data were corrected for the contribution of ${ }^{51} \mathrm{Cr}$ radioactivity to the ${ }^{125}$ I channel, caused by the energy overlap. The vascular and extravascular distribution of ${ }^{125} \mathrm{I}$ DNP-BSA at 15 minutes circulation time was calculated from the ratios between the measured radioactivity for ${ }^{51} \mathrm{Cr}$ and ${ }^{125} \mathrm{I}$ in the tissue and the corresponding specific activities were found for the two isotopes in the blood samples.

To compare the global permeability of the mesenteric circulation with that of other vascular beds endowed with the same continuous-type of endothelium, the diaphragm and tibialis anterior muscles were also harvested, weighed, and counted as before. Under the conditions of the experiment, only $5.9 \pm$ $1.0 \%(n=5)$ of the injected ${ }^{51} \mathrm{Cr}$ radioactivity was retained by the spleen. To check for the stability of ${ }^{51} \mathrm{Cr}$ association with the erythrocytes, a sample of the tracer was centrifuged at $800 \times g$ and the supernatant checked for ${ }^{51} \mathrm{Cr}$. Only $0.45 \%$ of this was found to be released from erythrocytes during a prolonged incubation (up to 5 hours) with DNP-BSA.

Morphometric Evaluation of DNP-BSA Presence in Mesentery. Five portions of mesenteric windows (the transparent membranous parts of the mesentery) were collected from each animal, postfixed for 90 minutes in $1 \% \mathrm{OsO}_{4}$, dehydrated in graded ethanol to minimize tissue shrinkage, and embedded in Epon 812. The technique of protein A-gold post-embedding immunocytochemistry described by Bendayan (1984) was applied for the ultrastructural localization of the DNPBSA. Thin sections $(50 \mathrm{~nm})$ of the embedded specimens were mounted on nickel grids, quenched for 30 minutes in PBS containing 1\% ovalbumin, and incubated for 2 hours at room temperature in anti-DNP 
antibody (Dako, Carpinteria, California) diluted 1:2,000 in ovalbumin-containing PBS, followed by 30 minutes in protein A conjugated with gold of $10-\mathrm{nm}$ particle diameter (Ghitescu and Bendayan, 1990). After staining with uranyl acetate and lead citrate, the sections were examined in a Philips 410 electron microscope.

The specificity of labeling for DNP in relation to the endogenous albumin was assayed by performing the same protocol on sections of mesenteric windows from animals that had not been injected with the tracer. This control proved that the nonspecific adsorption of the anti-DNP antibody or gold colloid to the tissue was virtually absent.

Morphometric measurements were made with a Zeiss-Videoplan 2 image processing system (Carl Zeiss, Toronto, Ontario, Canada). The labeling density was evaluated in the following compartments: the vascular lumen, the endothelial profile (nuclear zone excluded), endothelial basement membrane, interstitium, mesothelial basement membrane, and mesothelial cells, and were expressed as the number of gold particles per unit area $\left(\mu \mathrm{m}^{2}\right)$. The entire profile of the blood vessels was recorded and measured to evaluate the whole exchange surface of the endothelium. For each compartment, 70 to 90 images were examined. Statistical significance of the differences found between the diabetic and normoglycemic animals was validated by the Student's $t$ test. The distribution of the labeling within the endothelial and mesothelial basement membranes was also evaluated by calculating the ratio $(R)$ between the distance $(d)$ separating each gold particle from the abluminal plasma membrane of the mentioned cells and the thickness of the basement membrane $(D)$, measured at that point (Fig. 4). The values were expressed as the percentage of the total number of gold particles distributed across the endothelial or mesothelial basement membrane thickness divided in four successive intervals about 10-nm wide.

\section{Experiments Assessing the Caliber and the Density of the Mesentery Vascular Network}

This set of experiments was designed to provide an explanation for the marked increase in the blood volume recorded in the mesentery of diabetic animals.

Density of the Vascular Network within the Mesenteric Windows. The rat mesentery is composed of a membranous tissue divided into several "mesenteric windows" by fatty frames containing large branches of mesenteric arteries and veins (arcades). These windows are very thin and transparent, allowing for an easy observation of their microvasculature by light microscopy when spread on glass slides (Enerbäck et al, 1976).

Animals in this study were divided into four separate groups: 1) hyperglycemic rats, in which hyperglycemia was induced by ip injection of STZ; 2) rats that were ip injected with the same quantity of STZ, but did not reach significant hyperglycemic status; 3) hyperglycemic rats, in which hyperglycemia was induced by an iv injection of STZ, and 4) normoglycemic, age-matched control animals that did not receive the drug. Each group contained three animals.

Anesthetized rats were killed by cervical dislocation. The mesentery was immediately fixed in situ for 15 minutes by the ip injection of warm $4 \%$ buffered formaldehyde. The abdominal cavity was then opened and the intestines and mesentery were removed and further fixed overnight at $4^{\circ} \mathrm{C}$ with the same fixative. For each animal, a series of five adjacent mesenteric windows were selected, from the cecum to the duodenum. The mesenteric windows were spread on large glass slides and the microvessels visualized after staining with toluidine blue (Norrby, 1994). Images were photographically recorded with a Wild Photomakroskop M 400 and printed at magnifications of $25 \times$ to $128 \times$. On these images, morphometry was performed with the Videoplan 2 Image Analysis System, and the following parameters were measured: 1) total area of the mesenteric windows bordered by fatty arcada (arcada excluded); 2) the relative vascularized area (for each mesenteric window the areas containing blood vessels were outlined and measured, and the results expressed as a percentage of the total area for each mesenteric window); 3) the number of vascular ramifications (as an expression of the vascular network density, the total number of microvascular intersections or branchings was counted for each vascularized area); and 4) the total microvascular length (the length of microvessels between successive ramifications was measured and summed).

Caliber of the Vessels in the Mesenteric Arcades. The macrovascular segments of the mesentery are concentrated in the fatty arcades that divide the organ into the mesenteric windows. These arcades were cut from the previously fixed organs, oriented in a parallel bunch, and embedded in paraffin. For each animal, one block containing four or five such arcades was prepared. From each block, two $5-\mu \mathrm{m}$ thick sections were cut, 1-cm apart, perpendicular to the vessel axis and stained with hematoxylin-eosin. For all vessels with diameters greater than $30 \mu \mathrm{m}$ (approximately 60 profiles per animal), the circumference of their intima was measured and used to compute a hypothetical diameter for an assumed circular vascular profile. This approach was intended to compensate not as much for the relatively rare oblique sections, but for the irregular profile of some of the venous segments.

\section{Acknowledgements}

The authors are grateful to Mrs. Diane Gingras for her invaluable technical support. This paper represents part of the work for the fulfillment of a M.Sc. program by KA.

\section{References}

Aiello LP, Pierre EA, Foley ED, Takagi H, Chen H, Riddle L, Ferrara N, King GL, and Smith LEH (1995). Suppression of retinal neovascularization in vivo by inhibition of the vascular endothelial growth factor (VEGF) using soluble VEGFreceptor chimeric proteins. Proc Natl Acad Sci USA 92: 10457-10461. 
Armstrong D, Augustin AJ, Spengler R, Al-Jada A, Nikola T, Grus F, and Koch F (1998). Detection of vascular endothelial growth factor and tumor necrosis factor alpha in epiretinal membranes of proliferative diabetic retinopathy, proliferative vitreoretinopathy and macular pucker. Ophthalmologica 212: $410-414$

Ayo SH, Radnik RA, Garoni JA, Glass WF, and Kreisberg J (1990). High glucose causes an increase in extracellular matrix proteins in cultured mesangial cells. Am J Pathol 136:1339-1348.

Bazan NG, Gordon WC, Marcheselli VL, Lukiw WJ, Duhault J, Koenig-Berard E, Linn D, DeCoster MA, and Mukherjee PK (1997). Experimental models and their use in studies of diabetic retinal microangiopathy. Thérapie 52:447-451.

Beals CC, Bullock J, Jauregui R, and Duran WN (1993). Microvascular clearance of macromolecules in skeletal muscle of spontaneously diabetic rats. Microvasc Res 45:11-19.

Bendayan M (1984). Protein A-gold electron microscopic immunocytochemistry: Methods, applications, and limitations. J Electron Microsc Tech 1:243-270.

Bendayan M, Gingras D, and Charest P (1986). Distribution of endogenous albumin in the glomerular wall of streptozotocininduced diabetic rats as revealed by high-resolution immunocytochemistry. Diabetologia 29:868-875.

Bendayan M, Sandborn E, and Rasio E (1975). Studies of the capillary basal lamina. Lab Invest 32:757-767.

Boegehold MA (1998). Heterogeneity of endothelial function within the circulation. Curr Opinion Nephrol Hypertens 7:7178.

Cagliero E, Maiello M, Boeri D, Roy S, and Lorenzi M (1988). Increased expression of basement membrane components in human endothelial cells cultured in high glucose. J Clin Invest 82:735-738.

Cameron NE and Cotter MA (1997). The aetiopathogenesis of diabetic neuropathy: Vascular theories. In: Boulton AJM, editor. Diabetic neuropathy. Carnforth: Marius Press, 121146.

Colwell JA, Lopez-Virella M, and Winocour PD (1983). New concepts about the pathogenesis of atherosclerosis in diabetes mellitus. Am J Med 75:67-80.

Cunha-Vaz JG (1983). Studies on the pathophysiology of diabetic retinopathy. The blood-retinal barrier in diabetes. Diabetes 32:20-27.

Cunha-Vaz JG, Faria De Abreu JR, Campos AJ, and Figo GM (1975). Early breakdown of the blood retinal barrier in diabetes. $\mathrm{Br} \mathrm{J}$ Ophthalmol 59:649-656.

Doucet M, Londoño I, Gómez-Pascual A, and Bendayan M (2000). Glomerular basement membrane selective permeability in short-term streptozotocin-induced diabetic rats. Int $\mathrm{J}$ Exp Diabetes Res 1:19-30.

Enerbäck L, Franzén L, and Norrby K (1976). A tissue model for the study of cell proliferation parameters in vivo. Histochemistry 47:207-218.

Esser S, Wolburg K, Wolburg H, Breier G, Kurzchalia T, and Risau W (1998). Vascular endothelial growth factor induces endothelial fenestrations in vitro. J Cell Biol 140:947-959.

Feng Y, Venema VJ, Venema RC, Tsai N, Behzadian MA, and Caldwell RB (1999). VEGF-induced permeability increase is mediated by caveolae. Invest Ophthalmol Vis Sci 40:157167.
Fischer F and Gaertner J (1983). Morphometric analysis of basal laminae in rats with long-term streptozotocin diabetes. Exp Eye Res 37:55-64.

Flyvbjerg A (1997). Role of growth hormone, insulin-like growth factors (IGFs) and IGF-binding proteins in the renal complications of diabetes. Kidney Int Suppl 60:12-19.

Ghitescu L and Bendayan M (1990). Immunolabeling efficiency of protein A-gold complexes. J Histochem Cytochem 38:1523-1530.

Ghitescu L and Bendayan M (1992). Transendothelial transport of serum albumin: A quantitative immunocytochemical study. J Cell Biology 117:745-755.

Griffith G and Hoppeler H (1986). Quantitation in immunocytochemistry: Correlation of immunogold labeling to absolute number of membrane antigens. J Histochem Cytochem 34:1389-1398.

Hirata C, Nakano K, Nakamura N, Kitagawa Y, Shigeta H, Hasegawa G, Ogata M, Ikeda T, Sawa H, Nakamura K, lenaga K, Obayashi H, and Kondo M (1997). Advanced glycation end products induce expression of vascular endothelial growth factor by retinal Muller cells. Biochem Biophys Res Commun 236:712-715.

Hirose K, Østerby R, Nozawa M, and Gundersen HJG (1982). Development of glomerular lesions in experimental long-term diabetes in the rat. Kidney Int 21:689-695.

Johnson PC (1981). Non-vascular basement membrane thickening in diabetes mellitus. Lancet 2:932-933.

Kessler KF, Barth RF, and Wong KP (1982). Physicochemical studies of dinitrophenylated bovine serum albumin. Int J Pept Protein Res 20:73-80.

Kilzer P, Chang K, Marvel J, Rowold E, Jaudes P, Ullensvang S, Kilo C, and Williamson JR (1985). Albumin permeation of new vessels is increased in diabetic rats. Diabetes 34:333336.

Kitteringham NR, Magos JL, Newby S, and Park BK (1985). Drug-protein conjugate VIII. The metabolic fate of the dinitrophenyl hapten conjugated to albumin. Biochem Pharmacol 34:1763-1771.

Landis EM and Pappenhaimer JR (1963). Exchange of substances through the capillary wall. In: Hamilton W F and Dow P, editors. Handbook of Physiology, vol 2. Washington, DC: American Physiological Society, 961-1034.

Little JR and Eisen NH (1967). Preparation of immunogenic 2:4-dinitrophenyl and 2,4,6-trinitrophenic proteins. Methods Immunol Immunochem 1:128-133.

Liu J, Razani B, Tang S, Terman BI, Ware JA, and Lisanti MP (1999). Angiogenesis activators and inhibitors differentially regulate caveolin-1 expression and caveolae formation in vascular endothelial cells. Angiogenesis inhibitors block vascular endothelial growth factor-induced down-regulation of caveolin-1. J Biol Chem 274:15781-15785.

Londoño I, Ghitescu L, and Bendayan M (1995). Glomerular handling of circulating glycated albumin in the normal mouse kidney. Am J Physiol 268:F913-F921.

Lutty GA, McLeod DS, Merges C, Diggs A, and Plouet J (1996). Localization of vascular endothelial growth factor in human retina and choroid. Arch Ophthalmol 114:971-977.

Malcherek P and Franzén L (1991). A new model for the study of angiogenesis in connective tissue repair. Microvasc Res 42:217-223. 
Malik RA, Tesfaye S, Thompson SD, Verves A, Sharma AK, Boulton AJM, and Ward JD (1993). Endoneurial localization of microvascular damage in human diabetic neuropathy. Diabetologia 36:454-459.

Mauer SM, Steffes MW, Ellis EN, Sutherland DE, Brown DM, and Goetz FC (1984). Structural-functional relationships in diabetic nephropathy. J Clin Invest 74:1143-1155.

Myers BD, Winetz JA, Chui F, and Michaels AS (1982). Mechanism of proteinuria in diabetic nephropathy: A study of glomerular barrier function. Kidney Int 21:633-641.

Natarajan R, Bai W, Lanting L, Gonzales N, and Nadler J (1997). Effects of high glucose on vascular endothelial growth factor expression in vascular smooth muscle cells. Am J Physiol 273:H2224-H2231.

Neufeld G, Cohen T, Gengrinovitch S, and Poltorak Z (1999). Vascular endothelial growth factor (VEGF) and its receptors. FASEB J 13:9-22.

Norrby K (1994). Basic fibroblast growth factor and de novo mammalian angiogenesis. Microvasc Res 48:96-113.

Norrby K, Jakobsson A, Simonsen M, and Sörbo J. (1990a). Increased angiogenesis in diabetes. Experientia 46:856-860.

Norrby K, Jakobsson A, and Sörbo J. (1990b). Quantitative angiogenesis in spreads of intact rat mesenteric windows. Microvasc Res 39:341-348.

Nyengaard JR and Bendtsen TF (1993). The impact of experimental diabetes mellitus in rats on glomerular capillary number and sizes. Diabetologia 36:189-194.

O'Hare JA, Ferriss JB, Twomey B, and O'Sullivan DJ (1983). Poor metabolic control, hypertension, and microangiopathy independently increase the transcapillary escape rate of albumin in diabetes. Diabetologia 25:260-263

Østerby R (1986). Structural changes in the diabetic kidney. Clin Endocrinol Metab 15:733-751.

Palade GE (1960). Transport in quanta across the endothelium of blood capillaries. Anat Rec 136:254.

Parker JC, Falgout JH, Parker RE, Granger DN, and Taylor AE (1979). The effect of fluid volume loading on exclusion of interstitial albumin and lymph flow in the dog lung. Circ Res 45:440-450.

Parving HH (1975). Microvascular permeability to plasma proteins in hypertention and diabetes mellitus in man: On the pathogenesis of hypertensive and diabetic microangiopathy. Dan Med Bull 22:217-233.

Parving HH (1976). Increased microvascular permeability to plasma proteins in short- and long-term juvenile diabetics. Diabetes 25:884-889.

Pe'er J, Shweiki D, Itin A, Hemo I, Gnessin H, and Keshet E (1995). Hypoxia-induced expression of vascular endothelial growth factor by retinal cells is a common factor in neovascularizing ocular diseases. Lab Invest 72:638-645.

Porta M (1996). Endothelium: The main actor in remodelling of the retinal microvasculature in diabetes. Diabetologia 39:739-744.

Rajotte D, Arap W, Hagedorn M, Koivunen E, Pasqualini R, and Ruoslahti E (1998). Molecular heterogeneity of the vascular endothelium revealed by in vivo phage display. $\mathrm{J}$ Clin Invest 102:430-437.

Renard C, Chappey O, Wautier MP, Nagashima M, Lundh EL, Morser J, Zhao L, Schmidt AM, Schermann JM, and Wauthier
JL (1997). Recombinant advanced glycation end product receptor pharmacokinetics in normal and diabetic rats. Mol Pharmacol 52:54-62.

Roberts WG and Palade GE (1997). Neovasculature induced by vascular growth factor is fenestrated. Cancer Res 57:765762.

Roy S, Cagliero E, and Lorenzi M (1996). Fibronectin overexpression in retinal microvessels of patients with diabetes. Invest Ophthalmol Vis Sci 37:258-266.

Ruggiero D, Lecomte $M$, Michoud $F$, Lagarde $M$, and Wiernsperger N (1997). Involvement of cell-cell interactions in the pathogenesis of diabetic retinopathy. Diabetes Metab 23:30-42.

Shantaram V (1999). Pathogenesis of atherosclerosis in diabetes and hypertension. Clin Exp Hypertens 21:69-77.

Shweiki D, Itin A, Soffer D, and Keshet E (1992). Vascular endothelial growth factor induced by hypoxia may mediate hypoxia-initiated angiogenesis. Nature 359:843-845.

Simionescu N (1979). Enzymatic tracers in the study of vascular permeability. J Histochem Cytochem 27:11201130.

Simionescu N, Simionescu M, amd Palade GE (1975). Permeability of muscle capilaries to small heme-peptides. Evidence for the existence of patent transendothelial channels. $\mathrm{J}$ Cell Biol 64:424-452.

Slot JW, Posthuma G, Chang LY, Crapo GD, and Geuze HK (1989). Quantitative aspects of immunogold labeling in embedded and nonembedded sections. Am J Anat 185:271-281.

Steiner G (1997). Diabetes and atherosclerosis: A lipoprotein perspective. Diabet Med 14:S38-S44.

Tesfaye S, Malik R, and Ward JD (1994). Vascular factors in diabetic neuropathy. Diabetologia 37:847-854.

Thorin E and Shreeve SM (1998). Heterogeneity of vascular endothelial cells in normaland disease states. Pharmacol Ther 78:155-166.

Thüring U, Zimmermann D, and Bollinger A (1988). Studies of transcapillary diffusion in diabetic patients. Diabete Metab 14:527-529.

Trap-Jensen J (1971). Permeability of small vessels in diabetes. Acta Diabetol Lat 8(Suppl 1):192-200.

Trap-Jensen J and Lassen NA (1968). Increased capillary diffusion capacity for small ions in skeletal muscle in longterm diabetes. Scand J Clin Lab Invest 21:116-122.

Trap-Jensen $\mathrm{J}$ and Lassen NA (1970). Capillary permeability for smaller hydrophilic tracers in exercising skeletal muscle in normal man and in patients with long-term diabetes mellitus. In: Crone C and Lassen NA, editors. Capillary permeability. NewYork: Academic Press, 135-152.

Villaschi S, Johns L, Cirigliano M, and Pietra GG (1986). Binding and uptake of native glycosylated albumin-gold complexes in perfused rat lungs. Microvasc Res 32:190-199.

Vlassara H, Striker LJ, Teichberg S, Fuh H, Li YM, and Steffes $M$ (1994). Advanced glycation end products induce glomerular sclerosis and albuminuria in normal rats. Proc Natl Acad Sci USA 91:11704-11708.

Vranes D, Cooper ME, and Dilley RJ. (1995a). Angiotensinconverting enzyme inhibition reduces diabetes-induced vascular hypertrophy: Morphometric studies. J Vasc Res 32: 183-189. 
Vranes D, Dilley RJ, and Cooper ME. (1995b). Vascular changes in the diabetic kidney: Effects of ACE inhibition. $J$ Diabetes Complications 9:296-300.

Vranes D, Cooper ME, and Dilley RJ (1999). Cellular mechanisms of diabetic vascular hypertrophy. Microvasc Res 57: 8-18.

Williams B, Gallacher B, Patel H, and Orme C (1997). Glucose-induced protein kinase $C$ activation regulates vascular permeability factor mRNA expression and peptide production by human vascular smooth muscle cells in vitro. Diabetes 46:1497-1503.

Williamson JR, Chang K, Rowold E, Marvel J, Tomlinson M, Sherman WR, Ackermann KE, and Kilo C (1985). Sorbinil prevents diabetes-induced increases in vascular permeability but does not alter collagen cross-linking. Diabetes 34:703705.
Williamson JR, Chang K, Tilton RG, Prater C, Jefferey JR, Weigel C, Sharman WR, Eades DM, and Kilo C (1987). Increased vascular permeability in spontaneously diabetic BB/W rats and in rats with mild versus sever streptozotocininduced diabetes. Diabetes 36:813-821.

Yamaji T, Fukuhara T, and Kinoshita M (1993). Increased capillary permeablity to albumin in diabetic rat myocardium. Circ Res 72:947-957.

Yasuda H, Taniguchi Y, Yamashita M, Kobayashi N, Sonobe M, Hatanaka I, Kikkawa R, and Shigeta Y (1990). Morphological characteristics of dermal diabetic microangiopathy. Diabetes Res Clin Pract 9:187-194 